\title{
Effects of Cooperative Learning and Motivational Strategies for Older Adult on Functional Fitness
}

\author{
Wang, Hsiu-Hua ${ }^{1}$, Huang,Chin-Yun ${ }^{2}$,* \\ ${ }^{l}$ Department of Athletic Sports, Master Program in Sport and Leisure Education, Chung Cheng University, \\ Taiwan, R. O.C \\ ${ }^{2}$ Center of Physical Education, Nanhua University, Taiwan, R. O. C
}

*Corresponding Author: Huang,Chin-Yun, Center of Physical Education, Nanhua University, Taiwan, R. O. C

\begin{abstract}
The purpose of this study was to examine the effects of cooperative learning and the motivation strategies for older adults on performance, task on time and satisfaction from a multi component physical fitness program instruction perspective. After receiving specific training for implementing individual versus cooperative strategies, 56 older adults, classified as high and low need motivation for affiliation, were randomly assigned to treatments. An experimental method with a $2 x 2$ factorial design for the study. Participants completed a multi component physical fitness program, the effects of cooperative learning and motivational strategies were examined across posttest, time on task and satisfaction. Results revealed that Subjects who worked cooperatively summarized significantly more effective assessment than those who worked individually. This finding does appear to supports the large body of literature from physical activities instruction and traditional learning settings. In addition, the result revealed a significant interaction between instructional method and the need for affiliation, subjects with a low need for affiliation who worked alone performed worse than all other groups on the posttest. Furthermore, results revealed that subjects who worked cooperatively spent more time working on the practice exercises than those who worked individually. Results also revealed that subjects with a low need for affiliation spent significantly more time on task than those with a high need for affiliation. The data suggest that participants who worked cooperatively reported greater overall satisfaction with the instruction than those who worked individually. The implications for cooperative learning and motivation strategies to promote older adults for functional fitness instruction and future research are discussed.
\end{abstract}

Keywords: Cooperative Learning, Motivation Strategies, Older Adults, Functional Fitness

\section{INTRODUCTION}

With the increasing number of older adults and life expectancy, the issue of aging population has become more critical, leading to the growing prominence of problems related to elderly health care and treatment (Chang, 2015; Huang, Wei, \& Cheng, 2010). According to active aging proposed by the World Health Organization, participation (the creation of social participation channels), health (the establishment of an environment for physical and mental health), and security (social and economic security and life safety), as well as the comprehensive health promotion concept based on a fitness perspective that was developed by the American College of Sports Medicine (ACSM, 2016). These types of well-being complement each other and affect lifestyle and health quality in older adults.

As indicated by past studies, multiple complex factors influence exercise participation behavior in older adults; behavior of older adults can be changed through the use of appropriate learning systems, teaching methods, and interaction strategies (Bodsworth \& Goodyear, 2017; Jones, \& Rose, 2005; Rikli, \& Jones, (2001). Social interaction is a strong learning theory that, in addition to meaningful learning for older adults, focuses on balance transposition into real life (Huang, Wang, \& Lin, 2016). Social interaction emphasizes that learning is an important social situation that occurs within everyday cognition and interaction (O'Donoghue, 2016; Johnson \& Johnson, 1993). Such learning interaction originates from social relations, cultural history, specific commodities, real life situations, and physical activity learning environment. 
Cooperative learning is a feature of interaction instruction. The theory of cooperative learning advocates the importance of immersion into the learner's cultural background and effectiveness of learning in groups. According to the theory of cooperative learning, learning is reached through collaborative social interaction and social construction of balance (Fernandez-Rio., Sanz et al., 2016; Johnson \& Johnson, 1993). Such collaborative social interaction occurs only in a group.

Cooperative learning allows to assemble learners with different balance and experience into a jointly learning group, increasing diversity of learners' interaction partners and indirectly expanding their balance and skills (Bodsworth \& Goodyear, 2017; Barker, Quennerstedt, \& Annerstedt, 2015). According to Johnson and Johnson (1993), Cooperative learning can effectively improve higher-order cognitive processes. In a cooperative learning environment, members of small groups can observe and imitate each other and develop learning strategies; such interactive relationships enhance higher-order cognitive processes.

Some researchers report that cooperative learning positively affected performance in the instructional lessons (Dyson, 2014; Dyson, \& Casey, 2012; Artut, 2010). Others have not found a significant effect for performance and attitudes when learners used cooperative strategies (Carrier and Sales, 1987, Hooper, 1992). These differences in findings could be due to the types of learners who participated in domain of study. In addition, Research have reported that learner characteristics impact performance and motivation in cooperative studies. Factors such as personality, gender and ability have impacted outcomes in some of the studies. Researchers suggest that individuals' motivational characteristics may influence how they perform in cooperative environments (Hooper \& Hannafin, 1991; Johnson \& Johnson, 1993). According to Johnson and Johnson (1993), some individuals are more predisposed to act cooperatively, such people prefer cooperative settings over individual settings. The need for an affiliation is represented by a desire to participate in cooperative, noncompetitive activities and by a desire for close, friendly relationships with others (Slavin, 1990). Individuals with a high motivation need for affiliation are more friendly, sociable, and cooperative than those with a low motivation need for affiliation (Jackson, 1974). Motivational design theory in physical activities domain (Huang, Wang, Lin, 2016) suggests that older adults should be provided with opportunities for cooperative interaction to satisfy the motivation need for affiliation.

Although cooperative learning strategies were found to improve positive effects of interactive learning, there is a lack of research on the impacts of their use in motivational design on functional fitness improvement in older adults. This present study attempted to examine the effects of cooperative learning and the motivation strategies on functional fitness for older adults. The effects of cooperative learning and motivation need for affiliation were examined across posttest. More specifically, the following questions were addressed in this study: (1) Are there significant differences in the posttest performance between those who participated in cooperative learing and those who participated in individual learning condition? (2) Are there significant interactions between the motivation need for affiliation and cooperative conditions? (3) Will high affiliation older adults in the cooperative learning perform significantly better than those in the individual learning conditions? (4) Do older adults in cooperative treatment possess time on task and better satisfaction toward the instructional module than those in the individual treatment?

\section{METHOD}

\subsection{Participants}

Participants were 56 volunteer older adults (above 65 years old) enrolled in functional physical fitness program at senior center. While students in this class are required to participate in one research study during an instructional program, participation in this particular study was not mandatory. Participants had the option not to participate or withdraw from the study at any time. Participants were randomly assigned to one of two treatments cooperative or individual learning strategy and were assigned to one of two motivation need for affiliation categories-high or low. Participants were randomly assigned to treatments: 14 Participants in the individual learning/low-affiliation group, 14 in the individual learning/high-affiliation group, 14 in the cooperative learning/low-affiliation group, and 14 in the cooperative learning/high-affiliation group. 


\subsection{Materials}

Materials used in this study were an instructional functional physical fitness lesson, a motivation need for affiliation scale, an instrument to measure student motivation, and a functional physical fitness performance posttest.

The functional physical fitness lesson.

The core program principles and training methods (Rose and Jones, 2005) used in the study was designed to help the older adults build their basic performance skill in functional physical fitness. During the practicing stage, older adults received immediate feedback in specific skill areas by instructor. This unit is designed for self-instruction and group learning. The content presented in the program consists of five segments: 1) Principles warm-up and cool-down. 2) Flexibility training. 3) Resistance training. 4) Aerobic endurance training 5) Balance and mobility training (Rose and Jones, 2005). In pilot studies, the instructional lesson was reviewed and revised by two content experts and three functional physical fitness instructors. The instructional lesson was formatively evaluated using older adults of the target group, and was revised into its final form for instructional unite.

The affiliation scale of the Personality Research Form-E.

This scale consists of 16 items that measure the degree to which an individual is motivated to affiliate with others. A true/false format is used to indicate whether or not a person agrees with statements such as "Sometimes I have to make a real effort to be social" and "I spend lots of time visiting friends." According to Jackson (1974) study, the mean for this scale is $8.6(\mathrm{SD}=3.35)$ and that the internal consistency reliability is .86 when used with college students (Jackson, 1974). For participants in the current study the mean was 10.02 ( $\mathrm{SD}=3.66$ ), and the range was 1-16. A median split was used to assign participants to high and low categories of the motivation need for affiliation. Participants with scores at or above the median $(M d=12)$ were assigned to the high-affiliation category $(n=28)$ and those with scores below the median were assigned to the low-affiliation category $(\mathrm{n}=28)$.

The Instructional Materials Motivation Scale.

Motivation was measured using this scale including simple, safety, self-efficacy and Satisfaction (Huang, Wang \& Lin, 2017). This scale consists of six questions that measure student perceptions toward the motivational characteristics of instruction in the affective area of satisfaction. A five-point Likert scale is used to answer the questions. The Cronbach alpha internal-consistency relationship reliability estimate of this scale is .90 .

Posttest.

Tenth weeks after completing the instruction and practicing, all participants received a functional fitness of posttest. This posttest unit was adapted according to the standard senior functional fitness test (Rikli, \& Jones, 2001). The posttest was based on multicomponent of physical exercises intervention program on functional fitness. Data from the pilot studies were used to determine reliability estimates for posttest. Cronbach's alpha method was used to calculate the reliability of the posttest, and was found to have a value of .84 .

\subsection{Procedures}

The study was implemented during a ten-week period. The pretest was administered during the first week. The study consisted of five functional fitness instructional units. In addition, each group was given 20-minutes periods on skill practicing during the two to ninth week. Participants were randomly assigned to one of two treatment conditions, one which required subjects to work individually during the lesson and one which required subjects to work in group.

Participants received specific directions for implementing individual versus cooperative strategies. Participants who would be working alone were given a direction, instructed to work independently during the lesson, and told to do their best work. Participants who would be working in team were 
randomly assigned in the group. Each group was given a worksheet and told to work together and discuss the given feedback during the lesson. The purpose of the directions was given to the cooperative learning group's instructors to help reinforce those behaviors students need in order to work cooperatively (Johnson \& Johnson, 1993) The study was conducted the functional physical fitness program for instruction and skill practicing in the senior center. Upon completion the ninth week of the lesson, each participant individually completed the motivational scale on satisfaction questionnaire. The posttest was delivered in the final week of the study.

\subsection{Design and Data Analysis}

A $2 \times 2$ factorial design was used, with instructional method (individual versus cooperative) and need for achievement (high versus low) as the independent variables. The dependent variables were functional fitness on performance posttest, time on task, and a measure of participant's satisfaction.

Multivariate analysis of variance (MANOVA) was used to test for an overall difference between groups on the posttest. This analysis was followed by univariate analyses on the portions of the posttest and satisfaction. Alpha was set at .05 for all statistical tests. Effect size estimates (ES) expressed as a function of overall standard deviation were also calculated.

\section{RESULTS}

\subsection{Performance}

The first dependent variable of the study was student performance. This variable was operationally defined as an individual's score on the posttest. Mean scores and standard deviations for the posttest can be found in Table 1. Results indicated that instructional method had a significant main effect on posttest, $\underline{\mathrm{F}}(1,52)=3.96, \underline{\mathrm{MSe}}=2.85, \underline{\mathrm{ES}}=.53$. Subjects who worked cooperatively summarized significantly more effective assessment $(\mathrm{M}=4.86, \mathrm{SD}=1.76)$ than those who worked individually $(\mathrm{M}=3.96, \mathrm{SD}=1.56)$. Mean scores and standard deviations for the posttest can be found in Table 1 . Results for overall performance revealed a significant interaction between instructional method and the need for affiliation, $\underline{\mathrm{F}}(2,51)=3.63$. Follow-up multiple comparisons indicated a significant difference between high and low affiliation subjects in the individual condition, $F(3,52)=4.64$. Results also suggested significant differences between high affiliation subjects in the individual condition and low affiliation subjects in the cooperative condition, $\mathrm{F}(3,52)=4.33$, and between high affiliation subjects in each condition, $\mathrm{F}(3,52)=3.95$. As result reveals, subjects with a low need for affiliation who worked alone performed worse than all other groups on the posttest $(\mathrm{M}=2.75, \mathrm{SD}=$ 1.72).

\subsection{Time on Task}

Mean scores and standard deviations for time on task can be found in Table 1. Results revealed that type of instructional method had a significant effect on time on task, $\mathrm{F}(1,52)=68.03$, MSe $=15.21$, $\mathrm{ES}=.1 .48$. Subjects who worked cooperatively spent more time working on the practice exercises (M $=22.84, \mathrm{SD}=5.02)$ than those who worked individually $(\mathrm{M}=13.92, \mathrm{SD}=2.66)$. Results also suggested that subjects with a low need for affiliation spent significantly more time on task $(\mathrm{M}=$ $19.47, \mathrm{SD}=3.72)$ than those with a high need for affiliation $(\mathrm{M}=17.22, \mathrm{SD}=3.78),[\mathrm{F}(1,52)=4.61$, $\underline{\mathrm{MSe}}=15.21]$. Furthermore, a significant interaction for time on task was not found.

\subsection{Satisfaction}

Satisfaction was measured using the Instructional Materials Motivation Scale (Huang, Wang, Lin, 2016). Mean scores and standard deviations for satisfaction can be found in Table 1. Mean scores and standard deviations for each item on the satisfaction measure was given table 2. Results indicated that type of instructional method had a significant effect on satisfaction, $\underline{\mathrm{F}}(1,52)=4.87, \underline{\mathrm{MSe}}=28.45$, $\underline{\mathrm{ES}}$ $=.57$. Subjects who worked cooperatively reported greater satisfaction with the instruction $(\mathrm{M}=$ $18.54, \mathrm{SD}=5.63)$ than those who worked individually $(\mathrm{M}=15.44, \mathrm{SD}=4.86)$. No statistically significant differences in satisfaction were found for need for affiliation, or for the interaction between instructional method and need for affiliation. 
Table1: Mean Scores and Standard Deviations on the Outcome Measures of posttest, Time on Task (TOT), and Satisfaction

\begin{tabular}{|c|c|c|c|c|}
\hline \multirow{2}{*}{\multicolumn{2}{|c|}{ Condition }} & \multicolumn{3}{|c|}{ Outcome Measure } \\
\hline & & Posttest & TOT & Satisfaction \\
\hline \multicolumn{5}{|l|}{ Individual Learning } \\
\hline Low Affiliation & $\mathrm{M}$ & 2.75 & 14.56 & 14.52 \\
\hline$(\mathrm{n}=14)$ & SD & 1.71 & 2.97 & 3.80 \\
\hline High Affiliation & $\mathrm{M}$ & 4.16 & 13.45 & 16.20 \\
\hline$(n=14)$ & SD & 1.46 & 2.39 & 5.58 \\
\hline Total & $\mathrm{M}$ & 3.96 & 13.92 & 15.44 \\
\hline$(\mathrm{n}=28)$ & SD & 1.56 & 2.66 & 4.86 \\
\hline \multicolumn{5}{|l|}{ Cooperative Learning } \\
\hline Low Affiliation & $\mathrm{M}$ & 4.87 & 24.44 & 18.33 \\
\hline$(n=14)$ & SD & 1.60 & 4.47 & 5.72 \\
\hline High Affiliation & $\mathrm{M}$ & 4.85 & 20.99 & 18.77 \\
\hline$(n=14)$ & SD & 1.99 & 5.16 & 5.76 \\
\hline Total & $\mathrm{M}$ & 4.86 & 22.84 & 18.54 \\
\hline$(\mathrm{n}=28)$ & SD & 1.76 & 5.02 & 5.63 \\
\hline
\end{tabular}

*Note: Maximum possible score was ten for posttest and thirty for satisfaction

Table2. Means and Standard Deviations for Satisfaction items

\begin{tabular}{|l|l|l|l|l|l|l|}
\hline & \multicolumn{3}{c|}{ GROUP } \\
\hline \multicolumn{1}{|c|}{ Scale Item } & \multicolumn{2}{c|}{ Cooperative } & \multicolumn{2}{c|}{ Individual } & \multicolumn{2}{c|}{ Total } \\
\hline 1. Participation was satisfying & $\mathrm{M}$ & $\mathrm{SD}$ & $\mathrm{M}$ & SD & M & SD \\
\hline 2. Practice and skill were simple & 3.86 & 0.93 & 2.23 & 0.97 & 3.06 & 0.96 \\
\hline 3. Would like to participate in activity & 3.68 & 1.06 & 2.78 & 1.26 & 3.28 & 1.18 \\
\hline 4. Did not enjoy activity & 3.84 & 1.84 & 1.72 & 0.87 & 2.78 & 1.15 \\
\hline 5. Felt safety to complete activity & 2.94 & 1.48 & 3.75 & 1.08 & 3.34 & 1.34 \\
\hline 6. Activity was well designed & 3.38 & 1.22 & 2.67 & 1.26 & 2.95 & 1.30 \\
\hline
\end{tabular}

\section{DISCUSSION}

The purpose of this study was to investigate the effect of cooperative learning and motivational strategies for older adult on functional fitness. Subjects used either a cooperative or individual learning strategy while receiving the functional physical fitness training lesson, practice and feedback from an instructional program.

The most important finding to emerge from this study was that instructional method interacted with the need for affiliation on motivation to have an effect on performance. The results of this study lend support to others who indicate that cooperative learning positively affects student achievement, productivity, time on task, and attitude (Johnson \& Johnson, 1993; Slavin, 1990). Subjects with a low need for affiliation who worked alone performed worse than all other groups on the posttest. One possible explanation for this finding is that people with a low need for affiliation are less likely to be motivated and learn when instruction is presented via individual instructional design. Since students with a high affiliation motive prefer to participate in activities that allow them to work with others (Jackson, 1974; Simsek, \& Sales, 1993), physical activities for instructional module may not be an appropriate module of instruction for these individuals unless they interact with others about what is presented.

In the current study, subjects who worked cooperatively spent more time working on practice exercises, more skill information interaction immediately after instruction, and reported greater satisfaction than those who worked individually. One plausible explanation for the results obtained is that students in groups feel more supported and satisfied than other students.

This study has some implications for those who design instruction. Instructional functional fitness program can successfully increase older adult performance and motivation by employing cooperative groups in settings that were originally designed for individual learning. The current study suggests that cooperative learning and motivational strategies can be used with instructional activities lessons. The study also indicates that designers should consider student characteristics, for example, ability or 
different age group when assigning learners to instruction that requires them to work by themselves to accomplish goals.

Future studies should also examine other student characteristics that might influence outcomes in cooperative settings. The relatively short duration of the treatment and the effect of instructional control may have influenced the outcomes. Extending the experimental time for overall instruction could produce different results for satisfaction and performance. Further research should identify critical elements on function fitness under which effective interaction can be generated and maintained on the domain of functional fitness training setting for older adults.

\section{REFERENCES}

[1] American College of Sports Medicine. (2016). ACSM'S exercise for older adults. Philadelphia,USA.

[2] Artut, P. D. (2010). Experimental evaluation of the effectives of cooperative learning on kindergarten children's mathematics ability. International Journal of Educational Research, 48, 370-380.

[3] Barker, D., Quennerstedt, M. \& Annerstedt, C. (2015). Learning through group work in physical education: a symbolic interactionist approach. Journal of Sport, Education and Society, 20(5).

[4] Bodsworth, H. \& Goodyear, V. A. (2017). Barriers and facilitators to using digital technologies in the Cooperative Learning mod el in physical education, Physical Education and Sport Pedagogy.

[5] Carrier, C. A., \& Sales, G. C. (1987). Pair versus individual work on the acquisition of concepts in a computer-based instructional lesson. Journal of Computer-Based Instruction, 14, 11-17.

[6] Chang, L. Y. (2015). The effects of functional fitness for older people during core strength training program. Master Thesis, National Chung Cheng University.

[7] Dyson, B. (2014). Cooperative Learning: Cooperative Learning as a Transformative Pedagogy in Physical Education Cultura, Ciencia y Deporte, vol. 9, núm. 26, mayo-agosto, 2014, pp. 93-94. Universidad Católica San Antonio de Murcia, España.

[8] Dyson, B. (2005). Integration cooperative learning and tactical games models: Focus on social interactions and decision-making. In J. I. Bulter and L. L. Griffin (Eds.), Teaching games for understanding: Theory, research, and practive (pp. 149-168). Champaign, IL: Human Kinetics.

[9] Dyson, B., \& Casey, A. (Eds.). (2012). Cooperative learning in physical education: a research based approach. Routledge.

[10] Fernandez-Rio, J., Sanz, N., Fernandez-Cando, J., \& Santos, L. (2016). Impact of a sustained cooperative learning intervention on student motivation. Physical Education and Sport Pedagogy.

[11] Hooper, S. (1992). Effects of peer interaction during computer-based mathematics instruction. Journal of Educational Research and Development, 85 (3), 180-189.

[12] Hooper, S., \& Hannafin, M. J. (1991). The effects of group composition on achievement, interaction, and learning efficiency during computer-based cooperative instruction. Educational Technology Research and Development, 39 (3), 27-40.

[13] Huang, C. Y., Wei, H. C. \& Cheng, H. C. (2010). Relationship between regular exercise in older adults and successful aging: Model construction and indicator development and application. NSC Project Report.

[14] Huang, C. Y., Wang, H. H. \& Lin, M. J. (2016). The effects of functional physical and mental fitness platform for active ageing. Annual global report on Innovation in Active, Healthy and Smart Ageing Sector. Beijing Science \& Technology Publishing Press.

[15] Jackson, D. N. (1974). Personality research form manual. Goshen, NY: research Psychologists Press.

[16] Johnson, D. W., \& Johnson, R. T. (1993). Cooperative learning and feedback in technology-based instruction. In Dempsey, J., \& Sales, G. C. (Ed.), Interactive instruction and feedback. Englewood Cliffs, NJ: Educational Technology Publications.

[17] Jones, C.J., Rose, D. J. (2005). Physical Activity Instruction of Older Adults. Champaign, IL: Human Kinetics.

[18] O'Donoghue, R. (2016). Situated learning in relation to human conduct and social-ecological change, Schooling for Sustainable Development. pp25-38.

[19] Rikli, R. E., \& Jones, C. J. (2001). Senior fitness test manual. Champaign, IL: Human Kinetic.

[20] Simsek, A. \& Sales, G. C. (1993). The effects of instructional control on achievement, confidence, and attitudes in computer-based cooperative and individual learning. Journal of Computer-Based Instruction, 20(3), 81-86

[21] Slavin, R. E. (1990). Cooperative learning: Theory, research, and practice. Englewood Cliffs, NJ: Prentice Hall. 


\section{AUTHORS' BIOGRAPHY}

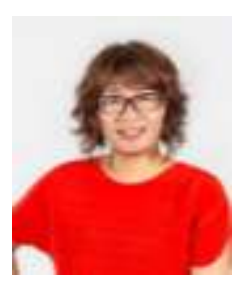

Professor Wang earned her PhD in fitness and health promotion at the Taiwan Sport University. Currently, teaches physical education in department of sport and leisure graduate program at National Chung-Cheng University and is also an external evaluator for the fitness and consultant at a fitness promotion for society senior citizens.

Professor Wang's field of expertise lies in sports and health promotion, sports pedagogy, Physical activity instruction of older adults, and the design of educational sports programs for active-aging learners.

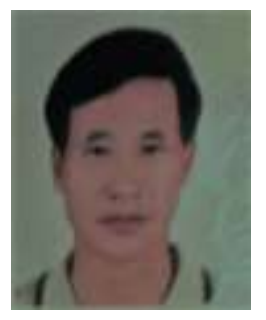

Professor Huang earned his $\mathrm{PhD}$ in education technology at the University of Minnesota. Currently, teaches physical education at Nanhua University and is also a designer and consultant on sports product for active aging. In addition, he is a consultant for the Active Aging Development Association Professor Huang's field of expertise lies in sports and health and leisure activities, sports pedagogy, instructional technology applications, and the development of physical and menal programs for active aging.

Citation: Wang, Hsiu-Hua, Huang,Chin-Yun. " Effects of Cooperative Learning and Motivational Strategies for Older Adult on Functional Fitness." International Journal of Humanities Social Sciences and Education (IJHSSE), vol 5, no. 1, 2018, pp. 105-111. doi: http://dx.doi.org/10.20431/2349-0381.0501016.

Copyright: ( $) 2018$ Authors. This is an open-access article distributed under the terms of the Creative Commons Attribution License, which permits unrestricted use, distribution, and reproduction in any medium, provided the original author and source are credited. 